\title{
Fearism and Racism: Investigating Middle Eastern Refugee Youth's Lived Experiences in the United States
}

\author{
Dilek Kayaalp
}

\section{Abstract}

In this study, I explore the social experiences of Middle Eastern refugee youth in the United States. Sixteen young people from Afghanistan, Iran, Iraq, and Syria aged 15 to 31 participated in this research. Hall's conceptualization of representation, Ahmed's cultural politics of emotion, Cohen's moral panic, and Fisher's fearism proved to be useful theoretical tools to examine refugee youth's experiences of marginalization and racism. To explore the refugee youths' lived experiences, I conducted a critical ethnographic inquiry. I conducted my fieldwork (in-depth interviews and participant observations) in Florida, for two years, from 2017 to 2019. The interview data indicate that racist narratives and misrepresentation of refugee youth negatively affect young people's experiences and social participation. In response, this study suggests continued investigation of the interplay between representation and fearism to decode state discourse and dominant cultural codes to provide alternative forms of social participation for refugee youth.

Keywords: fearism, racism, representation, Middle Eastern refugee youth, United States

\section{Introduction}

In this article I explore the relationship between fearism, racism, and representation of refugee youth as "fearsome strangers." Hall's conceptualization of representation, Ahmed's cultural politics of emotion and politics of fear, Fisher's fearism, and Cohen's moral panic are used as theoretical tools to examine the interplay between fearism, racism, and the lived experience of Middle Eastern refugee youth in the United States. My research questions are: i) How do these young people identify and position themselves? ii) What are their reactions to and perceptions of racism, fearism, and misrepresentation?

Fisher (2014) argues that fearism, like racism, is embedded in the dominant discourses of society. It is the outcome of an oppressive system which reproduces and maintains a fear-based culture. Fisher (2014) describes fearism as "the pathological ideology that keeps a fear-based culture as the hegemonic way of knowing and thus overdetermines the very understanding of fear itself" (p. 9). In this view, fear becomes 
a tool created and maintained by the dominant group to control and manipulate the general population.

Since fearism contributes to structural oppression within the fundamental trilogy of power, privilege, and domination, I wish to understand the relationship between fearism and racism, particularly how they reinforce and encourage each other. That is, how the refugee "other" becomes an agent of fear and what role racism plays in this construction. Although fearism and racism are both related to emotions (Ahmed, 2014), such as passions of racism, they cannot be reduced only to individual reactions. They are both the products of pathology and oppression operating at broader social levels, affecting many individuals and conditioning social relationships. Fisher (2014) argues that "fearism works continually on all levels of society and its institutions" (p. 11). Therefore, they are structural problems of society and the state. Sara Ahmed (2014) suggests that fear is an aspect of nationalism, a rational attitude of the dominant who think that they are in danger and need to protect themselves, their privileges and power, and their nation from the outsiders, including refugees and asylum seekers. Fear thus contributes to a constructed social and ideological imagination (Thompson, 1988). Ahmed (2014) takes the implications further, asserting that "emotions should not be regarded as psychological states, but as social and cultural practices" (p. 9).

In short, narratives and cultural practices which nurture fearism and racism are social products (Ahmed, 2014). They are created and circulated through collective memory, language, objects (material items), and images. These narratives portray minorities as dangerous outsiders, producing a hierarchy between a nation's "insiders" (the dominant group) and its "outsiders" (the refugees). In this hierarchy, refugees occupy the very bottom and have limited rights and restricted upward mobility. Fearism and racism combine to racialize the public space, segregating refugee youth spatially from the dominant group and constraining their behaviour; unlike the dominant group, refugee youth do not move much and occupy a smaller geographic area (Ahmed, 2014). Fear is used to suppress and control the refugee youth in order to "protect" the general population.

Examining racist and fearist narratives, i.e., systematically analyzing racist and fearful narratives about "others" (Fisher, 2014), requires exploring how and why these societal fears are reproduced by the official language of the state and supported by the mainstream population. One must examine those who are held in fear, as "the response of fear is itself dependent on particular narratives of what and who is fearsome" (Ahmed 2014, p. 69). In this particular study, I argue that the official language represents and defines refugee youth as fearsome outsiders. They are thus reduced to a linguistic sign that produces a meaning (Ahmed, 2014), which is circulated through the official language or representational system (Hall, 2013). As Hall (2013) put it, through representation "meaning is produced and exchanged between members of a culture" (p. 27). Hall continues, 
Representation is the production of the meaning of the concepts in our minds through language. It is the link between concepts and language which enables us to refer to either the 'real' world of objects, people or events, or indeed to imaginary worlds of fictional objects, people and events [my emphasis] (p. 29).

Representation, as a socially constructed and imaginary classification, categorization, and meaning-making practice, plays an important role in how we understand our world. We interpret and represent objects, people, and incidents through our knowledge (which is always subjective, partial, and shaped through personal experiences) and the culture we live in. Cultural references, codes, and norms are very difficult to un-learn as they are part of our group identity and individual experiences. As Hall argues (2013) "we are all, as it were, locked into our cultural perspectives or 'mind-sets"' (p. 8). Hall further explains that,

These codes are crucial for meaning and representation. They do not exist in nature but are the result of social conventions. They are a crucial part of our culture - our shared 'maps of meaning' - which we learn and unconsciously internalize as we become members of our culture. This constructionist approach to language thus introduces the symbolic domain of life, where words and things function as signs, into the very heart of social life itself. (p. 13)

Representation, in Hall's view, becomes a powerful tool to regulate social relations and negotiations. It may also become a dangerous medium in the hands of the dominant group which has the power to produce knowledge and represent or misrepresent ("untrue" representations) the other. The narrative of refugee youth as fearful outsiders is constructed and circulated at the pleasure of the dominant group, who fixes the meaning until the cultural codes change (though investigation of these cultural codes and decoding state rhetoric incites change).

In their study Policing the Crisis, Hall et al. (1978) indicate that conservative, authoritarian state discourses generate the idea of a crisis caused by immigrant youth and their violent acts. In response, the state claims the necessity of domination over the youth to protect its citizens. According to Hall et al. (1978), the increased state control and representation of refugee and immigrantyouth as the threats of social order are moments of crisis of the state, rather than crisis of society [emphasis mine]. The authors of Policing the Crisis show how

...the themes of race, crime and youth condensed into the image of mugging come to serve as the articulator of the crisis, as its ideological conductor. It is also about how these themes have functioned as a mechanism for the construction of an authoritarian consensus, a conservative backlash. (Hall et al., 1978, p. viii)

Similarly, Cohen's (1972) concept of moral panic explains how conservative discourses, including the mainstream's consensus, marginalizes young people and makes them agents of moral panic: 
Societies appear to be subject, every now and then, to periods of moral panic. A condition, episode, person or group of persons emerges to become defined as a threat to societal values and interests; its nature is presented in a stylized and stereo-typical fashion by the mass media; the moral barricades are manned by editors, bishops, politicians and other right-thinking people; socially accredited experts pronounced their solutions; ways of coping are evolved or resorted to...Sometimes the panic is passed over and is forgotten, except in folklore and collective memory; at other times it has more serious and long-lasting repercussions and might produce such changes as those in legal and social policy or even in the way society conceives itself." (p. 28)

According to Cohen (2002), moral panic comprises some ethical problems. While some significant issues are ignored or even denied (such as genocide or racism), some "harmless forms of rule-breaking" become historic threats in society. While the nature of moral panic can change from context to context, it is socially constructed. Cohen (2002, xxvi) argues that, "social problem construction always needs some form of enterprise. It does not, however, need a moral panic." As a result, the construction of refugees (and asylum seekers) as fearful others does not need a moral panic as refugees are the imagined threat or moral panic per se.

Similarly, according to Thompson (1998), any crisis that threatens social order causes moral panic. In this social crisis a group of people are depicted as a threat to the social order and the cause of the problem. While the "dangerous" (or the target) group changes according to the context and time, the dominant group is always portrayed as the victims though they have more power and privileges compared to the others. According to Thompson's analysis, context and political agenda are significant triggers of moral panic. Moral panic is created to divert attention from structural problems of society (such as poverty, inequality or racism).

Cohen (2002) argues that the vilification of refugees by the media and mainstream people leads to the representation of refugees as "bogus". Unlike "genuine" refugees, "bogus" refugees are seen as people who lie about their conditions. According to this narrative, they are merely economic migrants looking for better opportunities.

Using these theoretical perspectives on narratives of crisis and moral panic, I wish to explore the following questions to understand the interplay between fearism, racism, and the experiences of refugee youth in the US: What constitute a moral panic? What is the relationship between fearism, racism, representation, and moral panic? How are refugee youth constructed as the agents of moral panic and fear?

\section{Refugee Youth in the US}

Refugees in the US in recent years have faced many renewed difficulties, including grossly distorted misrepresentations. The Trump administration's xenophobic approach towards refugees and asylum seekers reclassified them as economic migrants who "chose" to move to the US, putting them in a vulnerable position without the usual refugee claims for state protection (Nawyn, 2018). This approach 
denies the painful experiences endured by refugee and asylum seekers while providing the government with justification to keep them out of the country. Moreover, the new policies reinforced the authority of the Trump administration to control the population of the country (Crossman, 2020). Through official language that reinforced the supremacy of "white" Americans, refugees were (mis)represented as illegal migrants and even criminals. They become a "morally untouchable category and a term of abuse" in schools and throughout American society (Cohen, 2011, xxii). For example, former president Donald Trump used such language explicitly when he directed his most dehumanizing and violent language toward migrants (Scott, 2019). ${ }^{1}$ The circulation of these racist narratives makes these imagined negativities into common-sense knowledge of the society (Kryzanowski, 2020).

In this anti-immigrant rhetoric, refugees from Middle Eastern countries were particularly demonized. According to Nawyn (2018), Trump's Muslim ban targeted Middle Eastern refugees from predominantly Muslim countries and constructed them as "criminals," "rapists" and "terrorists" (Colvin, 2018) ${ }^{2}$. As hatred and fear of Middle Eastern people grew, they became targets of Islamophobia regardless of their religious affiliation; many were Christians or non-Muslims of other beliefs. Perhaps in this context their specific identities mattered little, as they remained non-white and non-American, unassimilable foreigners in the eyes of American authorities and indeed of many Americans.

Representation of these asylum seekers and refugee youth as outcasts by the state and its formal institutions (broadcast media, organized religion, systems of education, etc.) or by "the circuit of culture" (the myriad informal yet influential cultural practices; see Hall, 1997a; 1997b) made refugee youth enemies of the nation. However, communicated, these representational practices fostered racism, fearism, and moral panic that separated the social and economic disadvantage of the refugees from the structural inequalities of the country, reducing the problems to crises of "race" and "refugees" while criminalizing the newcomers' differences. As Essed (2002) summarizes it, "racism must be understood as ideology, structure and process in which inequalities inherent in the wider social structure are related to biological and cultural factors attributed to those who are seen as a different 'race' and 'ethnic' group"' (p. 185). The state and its mainstream public respond with "the policing of

\footnotetext{
1 Trump reports "When the MS-13 comes in, when the other gang members come into our country, I refer to them as animals. [...] You wouldn't believe how bad these people are. These aren't people. These are animals (in Colvin, 2018). Similarly, in his Presidential announcement in 2016 Trump reports, "When Mexico sends its people, they're not sending their best. They're sending people that have lots of problems, and they're bringing those problems with us. They're bringing drugs. They're bringing crime. They're rapists (in Lee, 2017)."

2 In one of his speeches, Trump creates this untouchable category by criminalizing and scapegoating asylum seekers in the US. Trump reports, "the release of illegal immigrant criminals, drug dealers, gang members and violent predators into your community and providing safe harbor to some of the most vicious and violent offenders on earth." (in Colvin, 2018, p. x)
} 
difference" (Hall, 2000a). As Sager (2018) states, "the term 'crisis' is mobilized for political and ideological reasons. [...] The language of crisis is often connected to migration as well as racist and xenophobic ideologies" (p. 2).

\section{Methodology}

To explore Middle Eastern refugee youth's experiences in Florida, US, I conducted a critical ethnographic inquiry. I conducted in-depth interviews with 20 refugee youth (aged 15-31) and non-participant observations in different settings during a 24month period.

I participated in group gatherings and cultural events, including exhibitions, and seminars organized by refugee youth. I also conducted classroom observations and formal in-depth interviews with refugee youth from Syria, Iran, Iraq, and Afghanistan in a private school. My study was reviewed and approved by the Institutional Review Boards (IRB) of the University of North Florida.

My cultural background, as a woman from the Middle East, helped me build relationships with the refugee youth in Jacksonville (Florida) since we shared geographical origins and cultural similarities. I met my key informants and other participants during my daily, non-academic encounters (such as in a mosque or a Middle Eastern store in Jacksonville). Ethnographers advise that "long-term immersion in context increases the likelihood of spontaneously encountering important moments" (Arnould \& Wallendorf, 1994). My informal encounters helped me build trust relationships with my potential participants and led to invaluable exchanges of information.

During my data collection, I paid particular attention to what the youth left unsaid. For example, they generally avoided political issues. Many didn't talk about their refugee status-their fears, regrets, or the reasons they fled from their home country. They never mentioned the US invasion of Iraq and Afghanistan and its impact on their lives, creating conspicuous silences during our conversations. Ethically, a researcher cannot coerce study participants to discuss unpleasant topics, but moments of silences can be very revealing if the researcher understands the reasons for the participants' hesitations and fears.

\section{Findings}

Youth's self identification and their experiences of racism, fearism, and Islamophobia in the US formed central themes in this study. I argue that exploring refugee youth, their cultural background, and experiences requires examining their complex and transnational identities. Therefore, in this study, I investigate youth's lived experiences in the US and their pre-migration histories. Further, the data indicate that racism perpetuates fearism and vice versa. Young people become the object of fearfearsome others-due to racism, white supremacy, anti-immigrant policies and Islamophobia. 


\section{Refugee youths' identities}

My data show that young people are proud of their distinct personal characteristics, ethnic origins, and cultural identities. They regret that they had to leave their country of origin because of wars and political conflicts. Despite this pride, some youth report that they needed to adopt the norms, customs, and even the dominant ethnic identities of their host countries.

Their feelings of marginalization influence their social interactions, personal relationships, and identities. During my school observations, I noticed inter-group conflicts among young people primarily due to their ethnic origin (Iran or Iraq), religious affiliation (Christian or Muslim), and their English proficiency. This suggests that refugee youth's friendships are selective, as they choose friends only from a certain group of people. Friendships also appeared conditioned by historical context. For example, prolonged military conflicts between countries such as Iran and Iraq during the 1980s still affect the interactions between those of Iranian and Iraqi origin and their daily conflicts in the US.

Alex, one of my participants from Iraq, explains his self-identification and feelings of double marginalization as a Christian in Iraq and as a refugee in his two host countries of Turkey and the US.

Many people are dying in Iraq. Sunni and Shia people kill Christians-our people. DAESH tries to kill Christians more than Muslims. [...] In Turkey we stayed for 3 years. People in the middle school people were not nice. They were telling me 'you are from Iraq, you are ugly.' They were bullying. I don't want to change myself. Why don't you accept me as I am?

Alex continues to talk about his interactions with his peers and explains the importance of ethnicity (Arabic vs Persian heritage) in his friendship. Alex says "I don't like Iranians. They speak funny, they look funny."

Maddy, a young woman originally from Iraq, also describes her cultural identity and her emotional connection with her home country. Maddy says, "I consider myself as Iraqi because I was born there. I will never forget that. My family is in Iraq and we call them a lot."

Similarly, Tom talks about his regrets of fleeing from Iraq and his feelings of notbelonging in the US.

I feel bad about Iraq because people are hungry, they are fighting. Sometimes I don't feel I belong here [US]. Sometimes I am like “why am I here? Why can't I speak Arabic? Why am I not in my own country, speaking Arabic with my siblings? [...] After I went to Turkey, after 5 months, my grandmother died. She felt that my dad left her. She said to me, "I missed you a lot." I still remember our last conversation. One month later she passed. If we didn't leave, maybe she was still alive today. [...] If there was no war, I would live there (Iraq). 
Tom continues to explain how his interactions with peers negatively affects his selfidentification and sense of belonging. Tom states,

I am Christian. I speak Arabic and Syriac. I am not American. I am proud of my country [Iraq]. Some people say, 'you are stupid.' I say, 'thank you.' Sometimes friends help you, sometimes they push you in a negative way. They don't want you to get better.

Similarly, a comment by Jasmine, a young Muslim woman from Afghanistan, shows the interplay between peer pressure, Islamophobia, and the youth's cultural identification. Jasmine reports, "I started to wear headscarf once I moved to the US. They [her peers] were constantly mocking me and saying that 'you will go to hell, if you don't cover well.'”

My findings indicate that although many young people are proud of their ethnic origins and cultural identities, inter-group conflicts, cultural and historical contexts of their host and home countries affect their identity formations and social interactions.

\section{Youths' Reactions to Racism and Fearism}

Young people report that they are subject to racism and fearism in the US, as well as bullying and Islamophobia, because of their ethnic origin (Arab and Persian), their mother tongue (Arabic, Syriac), and their distinct cultural identities (including clothing, food, and other customs). Even more surprisingly, some of them report that they are subject to Islamophobia and stereotyping because of their Middle Eastern background though they are not Muslims. This in turn affects their sense of belonging. Some youth report that they do not feel they belong to the US and want to move back to their home country.

Some of them also state that they experienced racism and fearism in their country of origin because of their minority ethnic and religious status. Those of Kurdish Iraqi heritage, for example, or Syriac Orthodox religious beliefs faced prejudices at home and now find themselves "doubly marginalized" in the US and other host countries where they lived temporarily because of their additional status as Middle Eastern refugees.

Rosy explains her double marginalization in Iraq and the US because of her minoritized status as a Kurdish Muslim refugee woman. Rosy reports that Kurdish people and their culture have long been treated badly in Iraq. As a result, Kurdish people have been struggling with racism, poverty, and discrimination at many levels for many years. Rosy says,

People [Iraqi] think that Kurdish people have minds like a donkey [belittle Kurdish people]. They make fun of our traditional clothes [Kurdish men wear traditional pants]. They say, 'you are farmers.' We celebrate Newroz. They even don't want us to celebrate Newroz. 
Rosy's story indicates that her challenges have been complicated after her husband started to work in an American company, their personal situation worsened as the country's security declined and animosity rose towards people working in American companies. Eventually, they decided to move to the US. Rosy goes on to share her cultural challenges, like Islamophobia, after she migrated to the US. Rosy says,

Some people treat me badly because of my headscarf. One of my neighbours said "go back where you came from. This is not your country." I told her "You are old. I treat old people with respect." In the gym people are very bad and unfriendly. They ask me "what is this? [referring to her headscarf]" So, I put my hoody on to hide my headscarf.

Alex explains his experience of racism in the US with particular attention to language. Alex reports, "America is nice. But kids don't understand other cultures. They are racist. I speak four languages; they speak only one. That's not easy."

Maddy also experiences racism. She and her family lived in a refugee camp, Yarmuk, in Syria for six years. After the Syrian civil war started in 2011, they moved to the US. She explains her challenges in the US and recognizes the fear and hostility of mainstream Americans towards refugees:

I came here when I was young. The most difficult thing was to change schools and have no friends. Some of them [Americans] are not okay with refugees. Maybe they think this is their country. Maybe they are afraid of refugees.

Likewise, Tom's statements indicate that young people from the Middle East not only struggle with racism and bullying but also Islamophobia and fearism. Tom states,

Americans think that Arabic people are bad. But we have to show them we are good people, not bad. Some people think that you do not know anything, you are dumb, stupid. [...] Some people say, "this is America." They say, "you are a terrorist." 50\% of the people are like that. They will bully you. If you are from another country, they say "why don't you go back to your country." If you are Arabic and Muslim, they say "you bomb things." Sometimes people don't want to be friend with you because you are from Iraq.

Tom continues to describe his experiences, noting racism he and his family experienced from teachers in his own country, Iraq. Tom says,

My older brother was the best in school (in Iraq). But teachers didn't want him to be successful. We were Syriac Christians maybe that's why. In Iraq they put you down. We came here (US) to show people who we are.

These findings indicate that young people have been struggling with racism, misrepresentation, fearism, and inter-group conflicts daily in their social and educational circles. In addition, anti-immigrant policies and narratives, including state racism, have direct impacts on their lives and experiences. 


\section{Conclusion}

My analysis indicates that youth's self-identifications, interpersonal relationships, and day-to-day experiences are affected by the cultural context of the society, including the official narratives of racism, fearism (imagined social crisis), and misrepresentation (refugees as fearful others). In the American context, refugee youth's cultural identities, ethnic origins, and religious affiliations are a personal source of pride, but negatively affect their status and mobility, their identities, experiences, feelings of security, and their treatment by the social mainstream. Fearism and racism reinforce each other as young refugee people become the object and target of fear and mistreatment for their assumed fundamental qualities. Youth's experiences of racism, at times a double marginalization for being a minority in their home country and then being a Middle Eastern refugee in the host country, affect not only their socialization into American society, but also the social interactions among others from the Middle East. Ethnic conflicts among youth, particularly from Iran, Iraq, Syria, and Afghanistan are prevalent and visible.

As a result, I suggest ongoing investigation of the interplay between racism, fearism, and misrepresentation to help decode the discourses of the state and dominant cultural codes to provide alternative forms of participation and safe spaces for refugee youth.

\section{References}

[1] Ahmed, S. 2014. The cultural politics of emotion. UK: Edinburgh University Press.

[2] Arnould, E. \& Wallendorf, M. 1994. Market-Oriented Ethnography: Interpretation Building

[3] and Marketing Strategy Formulation. Journal of Marketing Research, 31, 484504.

[4] Cohen, S. 1972. Folk devils and moral panics: The creation of the mods and rockers. London: MacGibbon \& Kee.

[5] Cohen, S. 2002. Folk devils and moral panics. The creation of the mods and rockers. London: Routledge.

[6] Colvin, J. 2018. Trump defends "animal" remarks, says he will always use it. https://apnews.com/article/3c690381c5de49aea6103c9719568323

[7] Crossman, A. 2020. A Sociological understanding of moral panic. https://www.thoughtco.com/moral-panic-3026420

[8] Essed, P. 1991. Understanding everyday racism: An interdisciplinary theory. Newbury Park: Sage. 
[9] Fisher, M. 2014. Towards a theory of fearism. Carbondale, IL: In Search of Fearlessness Research Institute. http://hdl.handle.net/1880/110015.

[10] Hall, S., Critcher, C., Jefferson, T., Clarke, J. \& Roberts, B. 1978. Policing the crisis: mugging, the state and law and order. New York: Holmes \& Meier Publishers, Inc.

[11] Hall, S. 1997a. The work of representation. In S. Hall, Representation: cultural representations and signifying practices, 13-75. London: Sage.

[12] Hall, S. 1997b. The spectacle of the "other" In S. Hall, Representation: cultural representations and signifying practices (223-291). London: Sage.

[13] Hall, S. 2013. Representation: cultural representation and signifying practices. Sage Publications: London.

[14]Hall, S. 2000. Conclusion: The multicultural question. In B. Hesse (Ed.), Un/Settled multiculturalism: Diasporas, entanglements, "transruptions" (209-242). London: Zed Books.

[15] Kryzanowski, M. 2020. Discursive shifts and the normalisation of racism: imaginaries of immigration, moral panics and the discourse of contemporary right-wing populism. Social Semiotics, 30, 503-527.

[16] Lee, A. 2017. What did Donald Trump actually say about illegal immigrants? Odyssey.

[17] Nawyn, S. 2018. Refugees in the United States and the politics of crisis (pp. 163-181). The

[18] Oxford handbook of migration crises. Oxford: Oxford University Press.

[19] Sager, A. 2018. Ethics and migration crises (pp. 589-603). The Oxford handbook of migration

[20]crises. Oxford: Oxford University Press.

[21] Scott, E. 2019. Trump's most insulting and violent language is often reserved for immigrants.

[22] The Washington Post.

[23] Thompson, K. 1998. Moral panics. London: Routledge. 